\title{
The Identity Problem in the Diaspora Movies
}

\author{
Dr. Ammar Ibrahim Mohammed Al-Yasri, Ministry of Education, General Directorate of Holy Karbala \\ Education,ammaralyasri1972@gmail.com
}

\begin{abstract}
Diaspora cinema is one of the manifestations of cinematic genres whose manifestations linked to concepts such as immigration, exile, and moving away from the homeland. It is the cinema of immigrants who gathered in second countries within communities or minorities. Immigrants have suffered from many problems, the most important of which is the lack of integration and fragmentation of the concept of identity between the mother homeland and the new homeland. This is evident in their cinematic works. Therefore, chapter one of the present study includes the research problem that is centered around the following question:

What is the problem related to the concept of identity in the Diaspora cinema?

The chapter also includes the objectives, significance, and limits of the present study. Chapter two is divided into three sections. Section one is entitled Identity between the fixed and the transformed. Section two is entitled The process of the film form in the Diaspora cinema. Section three is entitled The concern of identity in the visual patterns of the Diaspora cinema. The chapter is concluded with a set of indicators. Chapter three includes the research community, the research sample, the research tool, and the analysis of the sample that the researcher selected for research necessities, which is the film of (Mirrors of the Diaspora) by the IraqiBritish director (Qassim Abd). Chapter four includes the results and conclusions. The present study ends with Arab and foreign references.
\end{abstract}

Keywords: Identity, problem, Diaspora, Movies.

Received: 05.12.2020 $\quad$ Accepted: 10.01.2021 $\quad$ Published: 08.02.2021

\section{Chapter One}

\section{THE METHODOLOGICAL FRAMEWORK}

\section{The research problem}

The concept of identity witnessed major structural transformations due to the colonial movement that sought to undermine the intellectual structures of the countries under colonialism. The intellectual structures varied between civilizational and cultural concepts, inheritance, science, and history. Colonialism falsified identity depending on its military and media system. The counterfeiting operations led To the fragmentation of the concept of identity externally as well because of colonialism, wars, and dictatorships. Many citizens of colonial countries migrated to exile and formed groups, races, and communities in these colonial states. New cultures of immigrants emerged through literary and artistic races of various kinds. Cinematic speech is one of those cultural speeches That have taken new labels.

Diaspora cinema is one of the manifestations of the cinematic manifestations of immigrants in various parts of the world. It has been associated with ethnic, racial and religious gatherings that did not fuse with the new culture in those countries despite the cosmopolitan claims to them. The reason seems to be the amount of spiritual alienation that minorities have suffered there, which is Alienation associated with the fragmentation of the concept of identity, whether in the tribal transformation of the motherland or its dimensional entity in the Diaspora. So, their cinematic works are with a specific problematic building and meaning; the privacy of the hero who suffers from the disorder of the concept of identity and the specificity of the film form that indicates fragmentation,. Through the researcher's observation of this film form, a research problem was put under the following question:

What are the problems related to the concept of identity in the Diaspora cinema?

2. The objectives.

The present study aims to reveal the problem of fragmentation of identity in the Diaspora cinema.

3. The significance of the present study. 
The significance of the present study is demonstrated by the complex topic it tackles. The problem of identity in cinema and the Diaspora cinema are the two concepts that are not addressed in cinematic literature in intellectual propositions. Besides, the present study is an addition to the benefit of workers in the cinematic field in application and theory.

4. The Limits.

1. The objective limit; This dimension is determined by the problems that led to the fragmentation of the concept of identity in the Diaspora cinema.

2. The spatial limit; Since Diaspora has no boundaries, the present study includes the discourse of the Diaspora cinema in the countries of Diaspora.

3. The temporal limit; This dimension includes cinematic works produced in the Diaspora countries since the beginning of the third millennium.

5. Defining terms.

The researcher did not mention any specification of the title terms because they are discussed extensively in chapter two.

\section{Chapter Two}

\section{THE THEORETICAL FRAMEWORK}

\section{Section one}

\section{Identity between the fixed and the transformational}

The concept of identity is one of the concepts that accompanied the human being since its first stage. Through it, various settlement groupings were formed between the main and subsidiary identities, whether ideological, religious, racial, ethnic, etc.. Identity is defined in linguistic dictionaries as "the truth of the thing or person that distinguishes it from Others. Or, it is a card in which the person's name, nationality, birth, and work is established. The truth is that the linguistic definition does not meet the identity of multiple identities and characteristics, but even philosophical, cultural, and social definitions do not define a specific concept but agree on general details such as social affiliation, language, and race. Alex Michelelli defines identity as "an entity that combines integrated affiliations with the identity of society as belonging to ethnic, religious, political or social groups". The identity may witness a structural flaw in its national concept with the political, cultural, and economic transformations caused by colonialism, external migration, and internal displacement. Muhammad Abd Abid Al-Jabri states that identity may witness a transformation due to its "negative and positive friction with other cultural identities that vary with it in some way". This means that the incoming conceptual heterogeneity undermines the previous social concepts, including customs, traditions, cultural heritage, and cultural and social structures, to show where new concepts may be accepted by some social groups. The other social groups feel a great spiritual alienation leading to social isolation on the one hand, and disruption of concepts such as citizenship, social integration, and alienation of cultural productions on the other hand. This cultural and social alienation associated with the fragmentation of the concept of identity makes individual entity incontinent and may contribute to compelling it to coercive coerce or optional exile, which leads to other conceptual shifts of identity. These transformations manifest themselves in a large way in the countries that fell under colonial domination, as in the Arab and African countries and other third world countries.

From Greek philosophy, through modern philosophy, to postmodern philosophy, most philosophers have discussed the concept of identity. The principle of identity in Aristotle is that "something is fixed and does not change with changing circumstances and conditions. It is expressed in this formula $(A=A)$. The principle of identity requires that something remains the same in every time and place".

The concept of identity developed with postmodern philosophers who studied the authoritarian dimensions that surround them as authoritarian pressures expose identity to deep spiritual fission which leads to its escape from its reality. The German philosopher Nietzsche considers the modern man as game of exclusion and marginalization due to the extremism of the religious, social, and political authorities that seek to cannibalize the human being within the concept of major narratives. The death of authority or the father represented the death of God was necessary for him. So, he cried in his book Zoroaster said so", "Let your will go toward making man be the meaning of this earth and its spirit". 
The French philosopher Michel Foucault believes that the foundations of madness and sexuality contributed greatly to the fragmentation of the human identity through his study of concepts. This is what seemed Clear in His book (Monitoring and Punishment) when he said that "the individual is facing the entire social body, and society is facing the individual to punish him ... an unequal struggle. It is noticed that the amount of condemnation of the authorities as a control institution that has made society its actual tool for monitoring identities in order to domesticate it within the herd policy led to the emergence of an existential anxiety of identity.

Colonial theorists did not differ from theorists of philosophy in their narratives on the transformations of identity. People who suffered from colonialism were subjected to a cultural devastation caused by the occupier, which led to a flaw in the concept of their social identity. The Palestinian-American theorist Edward Saeed believes that the eastern identity is damaged due to the colonial impasse until Orientalism became Easternized as "the effective and influential knowledge that delivered it to the West, which occupied and utilized its resources and persecuted it humanely with its help". This means that the existential alienation of identity made the Eastern to see that all colonial Western loads are permissible payloads. The black theorist Franz Fanon believes that that the colonizer has spread a radical culture that seeks to undermine the superiority of the Arab person derived from his rich history of accomplishments. The French colonizer thinks that the cerebral cortex of Algeria is underdeveloped. Others in Central Africa say that the African does not use the frontal lobes of the brain but only a little. Opposite to this authoritarian concept walled with violence, Fanon called to resist violence and persecution with violence and culture when he made his saying; "The intensification of the Violence among the occupied people will be appropriate with the violence practiced by the colonial regime". This debate, which arises on a violent colonial act and a similar reaction, casts a shadow over the identity that has lost its innocence. This matter was discussed by the theoreticians of the Asian minorities who tackled identity by virtue of Colonialism, such as Homi Baba, Gatteri Sabivac, and Anya Lomba. Homi Baba believes that the hybridization is "the colonial strategic coup that destroys national forces and constants by denying the discriminatory identities that include the original identity, which is only achieved Through distorting the original knowledge inheritance". Even countries that witnessed internal ethnic, racial, or sectarian wars, their identities were exposed to a defect that undermined their ancestral entity. This is what the Lebanese theorist Ali Harb believes as he described the civil war that he lived in Beirut; "even though The prevailing war in his country is not the same as all wars, as it is a complex war that has more than one face ... in which incompatible goals and slogans are mixed, which makes it difficult to understand and comprehend". Racism and sectarianism fragment the national predominant towards sub-identities. Hence, the problem occurs between the origins and branches is a problematic addition to the superficial problem with all its representations. Colonialism, in all its varieties, leads to distorting the above concepts.

Identity problems, whether authoritarianism, colonialism, or racial and sectarian retrenchment that made the human self suffer from a large mistake in understanding identity, distorting its prevailing certainties, which led to the alienation of identifiable identities, which made it seek to search for specific alternatives that might reach it with spiritual stability. The Diaspora is the ready alternatives, which made it fall victim to a new conceptual deprivation that indicates double alienation. The European and American identity is mostly the industry of the world of violence and consumption that makes the human goods a productive machine despite the health and social rights and the alleged liberties. The Diaspora theorist Rami Abu Shihab describes the fragmentation of belonging by saying; "The homeland has become an ambiguous state between a neglected homeland and an incomplete homeland. It is not a complete homeland. It is a place to live only. It belongs to another ethnic group".

The researcher believes that identity has witnessed internal divisions related to the authoritarian system on the one hand and the colonial space that undermined the references of national identity through its oppressive and cultural practice on the other hand, And external divisions related to the dreadful difference between incoming ID loads and cultural, social, economic, and political payloads in the new land.

The identity is largely formed in the aesthetic formulations in the literary and artistic races that cinematic discourse is one of its best manifestations. So, the cinematic discourses of the Diaspora are different in their formal structure due to the problem of identity on the one hand and the self-alienation that made the Diaspora a different cultural and aesthetic structure. The researcher addresses the process of the cinematic form of the Diaspora cinema and the modalities of the identity problem in the next two sections.

\section{Section two}




\section{The evolution of the film format in the Diaspora cinema}

The film format witnessed visual changes in its simulations since its early studies. The films of the brothers (Lumiere) established for the real current. The films (Millia) established the impressionistic or formal current. Then, the cinematic form witnessed formal and qualitative transformations. So, it is possible to hear about the forms of pure and avant-garde cinema, Clandestine work, and others on the one hand and types such as the war and historical film and others on the other hand due to the experimentation that the creative self yearns for. It is always tired of the dominant. Hence, it looks for different forms.

The movements of displacement, emigration, and emancipation with all its cultural manifestations produced multiple cinematic forms related to geography or idea at one time or both at other times. These forms are the French Boer cinema produced by the Arabs in the Diaspora, the Novo Brazilian cinema, and others.

The Diaspora cinema is one of the manifestations of the exile and immigration cinema. The meaning of the Diaspora has been mentioned in the dictionaries of the Arabic language in the sense of separation. It is said: "I fear the Diaspora over you, that is the separation". They separate people, some of whom have done good, and some of them who have done evil". The word has been found in the Encyclopedia as a term that refers to the places where immigrant people are located in different regions of the world to become dispersed as separate groups and interact by various means.

Since ancient times, slavery, family, and displacement processes have contributed to global sociocultural changes that have reached their most intense in the sixteenth century when the black were sold to the new world followed by numerous migrations such as the emigration of the children of Palestine, the Asian or African minorities forced or voluntary migrations due to colonial, political circumstances, or Economic or the vision of the civilized world. These minorities inhabited in close proximity, whether random for the transcendent or civil for the naturalized, which led to the emergence of a cultural discourse for this Diaspora. The middle and the end of the last century witnessed the flow of migrations to Europe and America for various reasons. The cinematographic industry of the Diaspora was manifested under various names, including the Boer cinema of the Arab Diaspora in France, the singular means according to the folk tale of the French Arabs as it indicates "the confusion and hesitation associated with the identity of the two cultures". The French nationality is between the French of Maghreb origin and the immigrant father from North Africa". It is the cinema of the Arab Diaspora from Morocco, Tunisia, and Algeria who are on the outskirts of French cities. It is the cinema of the generation of fragmentation of identities and European racism. Repeated in this cinema is "the reality of the multiple races in cities, where unemployment, street crime, poverty, state control, organizations and laws, and institutional, social and racial personal consequences". Racial diversity, noninclusion, discrimination, racism, and nestalogy became the dominant themes in their cinematic discourse. Being isolated from The French Cinematographic Foundation, they resorted to establishing their independent cinematic entity. Films such as Bye Bay, Five, and Chouf by the French Arab director Kareem Dreidi reveal that topics such as isolation, alienation, non-integration, racism, and loss of identity are permissible in these films in a manner that establishes a cinematic discourse that does not resemble only itself, that is, "the Diaspora cinema destroys the concept of national cinema and reconsiders it by emphasizing the heterogeneity and pluralism by presenting those others who were distracted from their homelands due to economic migration and the legacy of colonial imperialism.

As for the Palestinian Diaspora, since the first and mid-century migrations, it has suffered from many internal identity problems, including in the mother country, such as land deprivation, distortion of history, the disintegration of the tribe, etc., and external ones such as racism, anti-Arabism, contempt of religions, and advocacy of the Zionist occupant, which made the immigrant self tend to Undermining these problems through many cultural races, including the Diaspora cinema, which discussed these problems with Nestlology phenomenon. The Palestinian cinematic Diaspora may be distributed in many continents such as America, Europe, and Australia. Their actions were not without the identity problems. The movie The Wedding of Galilee for the Palestinian-Belgian director Michel Khleifi embodies the conflict between the original Palestinian culture and the incoming Zionist culture through the desire to hold a wedding amid the prevention of usurping Zionist forces. The director has strengthened his visual construction with many indicative codes, including the Arab horse trapped between minefields, which is a sign that the identity and the body are strange. Anna Paul described the undermining of the Palestinian identity and its cultural structure. She states that "Arab masculinity is traditionally based on a strict code of honor that is based on 
preserving face, kinship, and participation ... but its cultural capital is undermined by the political power of the Israelis".

The beginning of the last century witnessed wide African migrations to America to be added to black people who were brought through slavery. The black race suffered in the beginnings to attempts to obliterate the human identity through slavery associated with violence, ignorance and disease. But, the situation reached in the cinema that the American white actor's face is polished black in order to play the role of the booby nigger. But, the black Diaspora cinema struggled alongside the political struggle until it was able to establish its first steps with the movie of Shaft in the seventies. This opened to a culture that established it, such as Hip Hop arts. The margin lying in the back streets rejects colonial culture despite its presence in the country. Black cinema continued its aesthetic struggle until the movie 12 slaves was produced in 2012 by the director Steve McQueen. It dismantled the system of Academy Awards associated with white race when it received the Oscar. The story of championship, directing, production, and most of the artists were of the black race who established their independent cinematic discourse. It is noticeable in black cinema films such as Mandela and chief butler that for a mother not to integrate with the new racist culture, black assemblies were isolated in dilapidated buildings and they were working in menial occupations. They have their different cultural structure. They presented problematic issues such as originality and hybridization during their work against the basic stereotypical figures that were devoted to the media in addition to maintaining a political inclusion based on a shared ethnic and cultural identity".

As for the Indian Diaspora in the American continent, it has suffered from a misconception of concepts such as authenticity of identity and integration. This is what was clear in the films that the immigrants produced there. The movie Masala produced in 1995 by the Indian Canadian director Srinivas Krishna reveals the concepts of losing the Diaspora who failed Their homelands by working in humiliated professions, drug addiction, and existential anxiety were a continent of the Indian Diaspora in Canada. This was embodied through the relational system of the movie of Krishna with social surroundings. The family and their nation lost street cleaning, the scenes of nestalogia mixed with the harshness of the laws of integration. Racism and violence were the masters of the film, which established for the Indian Diaspora cinema discourse.

Since the middle of the last century, the Iraqis were subjected to structural transformations that disrupted their existential existence. After that, the Jews of Iraq emigrated. Then, the period of the Baath Party at the end of the sixties was witnessed. The migration of the Communists followed at the beginning of the nineties. A third migration was due to the economic blockade. The beginning of the third millennium witnessed a large migration due to the American occupation and the outbreak of sectarian war. Migrations varied. They are either ideological, religious, or economic, whether forced or voluntary. The Iraqi Diaspora may be distributed in many continents such as Europe, Australia and America. Topics such as religion, identity, ideology, belonging and integration have formed The visual references for the Iraqi Diaspora cinema. Films by the directors Samir Jamal Al-Din, Qassim Abd), Qutaiba Al-Janabi, and Jaafar Murad clearly indicate that. In the film of Baghdad in my imagination produced in 2019 by the Iraqi Swiss director Samir Jamal Al-Din, it is noticed that the supposed place for events is (Abu Nuwas) Café in central London. So, the cafe is the mini homeland that represents Iraq. The characters are the owner of the cafe who is from the Kurdish nationalism, the main character is a communist poet who fled from the regime of Saddam, the third character working in the cafe is a Christian who fled From the religious persecution, and the fourth character is from the new immigrants. The apparent and implicit formats in the film discuss the displacement of the indigenous Iraqis and the concerns of integration and religious and tribal extremism, which led to a fog in the concept of identity that emerged through the questions such as; Is the Iraqi identity repelling religious minorities, authentic political affiliations, and ethnic nationalities?

\section{Section three}

\section{Identity anxiety in the visual formats of the Diaspora cinema}

The audiovisual formats are a mutually supportive system of cinematic language in a controlled form in order to achieve their conceptual goals. The manifestations of identity are manifested in all its fragments through this systematic structure of the film form in the structure of the image.

The body is a dominant central format in the Diaspora films as it is the system that adheres to other forms. It is the main driver of the character that is the wheel of events and fueling conflict and peaks leading to purification. In the movie of The Iraqi Odyssey produced in 2016 by the director Samir Jamal Al-Din), it is 
noticed that the characters of the family that the film deals with suffer from identity problems because of political and religious transformations in Iraq. The sister, uncle, and aunt were participating in interviews and explaining video and photographic documents about their lives from the monarchy to the present day. The camera angles show the degree of fragmentation of the narrative voices. In the scene in which the hero turns the reading material curriculum that was taught at his elementary school decades ago in an indication of communication with his roots, the high angles indicate the amount of alienation he experienced in the Diaspora in London, and the same angle was repeated in the scene of his aunt in her home in New Zealand, as well as the layer of sound that was telling the amount of nostalgia to the land that rejected them because of the governments.

As for the rest of the elements of the cinematic language, it contributed to highlighting the philosophy of fragmenting the identity of the body that suffers from the Diaspora illuminated through the struggle between shadow and light which embodied the amount of looting and pain that the body suffered. The work makers intentionally placed the body in the dark or subjected it to layers of light of the low level or the source of the lighting should be on one side of the face so that the second side is dark in a semantic referral indicating the anxiety and alienation of the character as in the film of Babisha produced in 2019 by the French Algerian director Monia Midor. The American theorist Ken Dansiger says: "Illumination can be used to focus on victims, and on those who turn them into victims, before the narrative narration results in the fate of these characters". Camera angles and footage sizes dominated the problematic identity domination, shaky staffs, sometimes high angles, and close-up shots attached to Concern of the characters recalling country in a hazy way on the one hand and instability in the new homeland on the other hand. The anxiety that surrounds their lives, which causes the characters to fall into a spatial dislocation between the place of childhood and adolescence stuck in the folds of memory, such as Karrada, Al-Rashid Street, and Mansour Street, and the current location of presence in Britain, America, and New Zealand. Assets, bodies, decorations, costumes, and accessories no longer refer the recipient to the structure of the event, but they were also strangely exotic. This spatial instinct became a necessary feature of the cinema of the Diaspora and the essence of its sensitivity. Marcel Martin described the place as "the general form of the intrinsic sensitivity of the cinema as a visual art". The fashion does not differ from the place. It was indicative of the apparent presence in exile without being attached to the civilization of that country. It was not with environmental references that refer to a specific heritage, customs, or traditions but rather it is Civil clothing in general. The accessories have shown identity problems as well. In the movie of My Girlfriend Villa produced in 2019 by the African-Brazilian director Jules Zito Arajo, it is noticed that the outstanding family photos refer to the mother African country, but the other Accessories; hanging watches and global panels indicate the identity of the country of the Diaspora. This dialectical dualism has created identity references in the structure of work. The identity relates to the environment, customs, traditions, and styles of living and education that a group of individuals live in. When these references are fragmented, the recipient finds himself opposite a fragmented cinematic work towards various identity references. This disturbs the concept of identity. The decorations and buildings embodied the new homeland in the Diaspora as they are forced visuals imposed on its inhabitants, but it suffered from an existential incompatibility with the accessories and bodies that remained associated with the first ethnic process, which made the Diaspora films suffer from the inconsistency of the elements of the cinematic language In a controlled form. Hence, the figure became a semantic structure indicating identity disorganization.

The elements of the cinematic language visually flowing according to a consistent formal structure seeking to communicate its philosophical message through two themes. The first theme is objective. The second theme is technical aesthetic. The two themes overlap with each other to reach the presumed ends, but the films of the Diaspora cinema violated this concept due to the fragmentation of its subjects between the motherland and homeland Diaspora. This fragmentation was reflected in the failure of concepts of cinematic language and film format.

\section{Theoretical framework indicators}

1. The colonial policies and the oppressive authorities in their various religious, social, political, ethnic, and sectarian varieties in the motherland are among the reasons for the fragmentation of identity among the filmmakers of the Diaspora films.

2. The subjects of anti-authoritarianism, nostalgia, race, poverty, non-integration, and existential alienation are characteristics of the Diaspora movies. 
3. The elements of the cinematic language are working to highlight the problems of identity in the Diaspora cinema films by employing their aesthetics that relate to anxiety, alienation, nostalgia, nonintegration, and so on.

\section{Chapter Three}

\section{The research Procedures}

1. The research Methodology; In order to achieve the objectives of the present study, the researcher chose the descriptive approach. The researcher uses the content analysis method as one of the tools.

2. The research community; The research community includes many cinematic films that belong to the Diaspora cinema. The researcher chose an intentional sample.

3. The research sample; The movie of Mirrors of the Diaspora directed by the Iraqi-British director Qassim Abd. It fits the objectives of the present study on the one hand and because it belongs to the Iraqi identity that the researcher belongs to on the other hand, which facilitates the reading of its artistic and aesthetic payloads.

4. The sample analysis.

The Film name: Mirrors of the Diaspora.

Production year: 2017.

Production agency: Qassim Abd/ Britain.

Photography: Qassim Abd.

Editor: Qassim Abd.

Director: Qassim Abd.

Film duration: 87 minutes.

Film synopsis.

The film shows the compulsory exile of Iraqi artists who were expelled outside the walls of the country for various reasons, most notably the cruelty of political, social, and religious authority during the rule of the dictatorial Baath regime. Through their narrative voices, one feels the political disappointment that swept them after the events of 2003. Their dream was to return to the walls of the country after the collapse of the dictatorial regime. The narrative voices varied in the film. The first narrative voice is for the Iraqi artist Afifa Laibi residing in the Netherlands. She initially suffered from the cruelty of exile. But, she struggled for the sake of merging later. The second narrative voice is the artist (Ali) residing in Rome who inspired his artwork from European civilization. The third voice is the Kurdish sculptor who works in a highlevel operator of technology. The fourth voice is the artist Jabbar Alwan whose a studio in Rome is a place where these anxious voices meet. The fifth voice is the artist Kadhim residing in Sweden who suffers from the same alienation surrounding other voices as well as other artistic voices suffered from the same existential anxiety.

The first indicator; The colonial policies and the oppressive authorities in their various religious, social, political, ethnic and sectarian varieties in the motherland are among the reasons for the fragmentation of identity among the filmmakers of the Diaspora films.

Following the characters of the film reveals that they are under oppressive pressures, whether colonial or internal authoritarian whose intellectual and psychological manifestations reflected on the body to search for a new homeland to preserve its existential entity. The plastic artist Al-Alaq did not forget his brother who was executed in the sixties, which made his motherland A place chasing him. The security men investigate him most of the time, which made childhood memories fade with the passage of time and the familiar and faithful place turned into a place where he was expelled and forced to live to experience the harsh life of the exile. So, he has no choice but to struggle with the new presence in which he was placed. He must prove himself through Integration by learning the language, order, customs, traditions, etc. Hence, the body fell under a bitter existential injustice manifested through intense psychological conflict between the tribal loads of the motherland and the distant loads of the new homeland, which made the character fragment identities. This is embodied through his artistic works. In the sixth minute, it is noticed that the artist creates a sculptural artwork in a collage manner embodying the execution of his brother in Iraq. The inverted chair from which the red threads hanged embodies the brutality of the torture chair and The blood of tortured people during the Saddam's reign. The black background indicates the darkness of the ruling regime. The agricultural soil and water were placed on the floor indicating that the victims will worship life for future generations. Although the raw material is from the land of exile but the memories of the homeland left Its 
impact on the structure of the work. After the work proved its artistic and cultural presence in the country of exile, it contributed to the consolidation of its identity as an artist recognized by the cultural institution there so that the body lived an identity problem between the mother country and the exile. The cultural and civilizational features, customs and traditions of the new country do not materialize, but rather a scene of executing the brother. According to his artistic imagination, the director of the film puts viewers before plastic worlds expressing a cynical expression of the artist's self-perspective. The same situation was embodied in the scenes of the plastic artist Afifa Allibi whose true belonging to the Netherlands which became the alternative place for her country, which was dominated by a patriarchal culture par excellence even after 2003 with The control of the radical religious authority that makes women ever subject to compulsive hierarchy announced in its missionary speech. The fifty-third minute of the film shows the amount of authoritarian violence she suffered in Basra after her return from the desertion due to the lack of her wearing the hijab, which created a new existential rift in itself that caused her to leave for her Dutch exile again so that this would fall into an identity problem in her work. The colors express the Dutch nature while the subjects embody the spiritual oppression that she suffered In Iraq. The artist Kadhim Al-Dakhil did not differ from his colleagues from the plastic artists since the extreme cruelty before 2003 and the scenes of slaughter during the sectarian war in 2007 made the country a dream that is no longer a dream. These cruel scenes distorted the concept of the artistic identity of the new homeland. He did not open up to his customs, traditions, legacies and civilizations, which made the people of the new country see him as an immigrant who could not give up his previous loads. The same situation is observed in the theatrical scene presented by the Palestinian actor in the fifteenth minute when he was described as a refugee who sold his country. This concern that the characters suffered was Reflected on the film's structure as a comprehensive semantic unit whose message is addressed to the recipient. The film's director is a migrant who has fragmented concepts of identity. He was unable to emulate his artistic legacies on the one hand and On the other hand, the British exile was lost due to the oppressive powers suffered by its heroes.

The second indicator; Anti-authoritarian, anti-natalogy, racial, poverty, non-inclusion and existential alien themes are features of the Diaspora movies.

The film's director deliberately opposed the authoritarian act with its various social, political and religious extremes, whether it was before the fall of the dictatorial regime in Iraq or after it through the central theme of the film, which was embodied by the concern of its heroes who fell under the injustice of these authorities. In the tenth minute, the Kurdish sculptor spoke of his work that was presented In Europe. He personified the person wounded in the wars that the Iraqis suffered from, alienation, economic want, and psychological retardation in contact with his Iraqi heritage by employing the wounded Assyrian lions statues. In the fifty-second minute of the film when the artist; the intruder talked about the scene of the slaughter of the cow and beheaded In his former country, Iraq, which made him lose consciousness, these scenes are considered a destructive act of violence in his country and a cry of condemnation on the one hand and an attempt to reshape the collective consciousness towards love and peace on the other hand. The photographs included in the film were either by Afifa or by the Kurdish letters with nostalgia for the past. In the fifty-sixth minute of the film, the structure of the present is noticed. The theme of races and religions did not disappear from the movie. The narrative voices varied between the Arab, Kurdish, Southern, Northern, Muslim, and Christian for the identity emerged from its narrow descriptions of sub-identities in the mother country towards a problematic concept centered on two forms of lost fog and tribal identity and a dimensional identity whose concepts have not yet been formed in the Diaspora. The director of the film employed themes such as poverty and unemployment suffered by immigrants. Afifa suffered from lack of work at the beginning of her migration. The same situation was suffered by others. So, the Diaspora believes in productive humanity, meaning that the existence of the self depends on its ability to work, produce, and then integrate. This is embodied in the forty-fourth minute after Afifa emerged an important artistic name in the exhibition halls to marry the Dutch professor on her spiritual journey towards integration. The spiritual alienation dependent on anxiety of identity was a well-established theme that dominates All the narrative voices in the film because Iraq chases them everywhere and the displaced did not reach the stage of spatial domination. This is what was embodied in the Iraqi painter's dialogue in the eighty-third minute when he said: As for me, I lived in the East and got to know the West, so I did not find my humanity on the first and I did not find my country on the second.

The third indicator; The elements of the cinematic language are working to highlight the problems of identity in the Diaspora cinema films by employing their aesthetics that relate to anxiety, alienation, nostalgia, non-integration, etc. 
The elements of the cinematic language demonstrated through the film form are the means by which the message of the film is communicated to the recipient as an influential actor. The shooting angles, the size of the shots and the camera movements showed the amount of anxiety that the characters experienced as the first crossing of the directive vision. In the scenes of the artist's Afifa whether it is at the beginning or in the middle of the movie, the employment of angles of the level of view that indicates realism, the recipient is a realistic existentialist who must be persuaded by it. In other cases, the director resorted to using the high angles that show the amount of existential pressure experienced by the characters. The director intended to use The portable camera in most of the joints of the movie. This shaky camera indicates the anxiety of the internal characters on one side and the realistic employment of the camera in an approach with the human eye shaken by the walk on the other hand. The close-up shots of the faces showed the amount of pain experienced by the characters as anxious characters tend to depend with increasing In the movements of the face and hands as seen in the scenes of all artists. The lighting did not differ from photography in the embodiment of reality as the director did not use any Industrial lighting that distorts the document. The tenth minute shows that the middle shot that was photographed from the angle of the Kurdish artist's visual level was done by natural lighting without the use of any filters. The clothes worn by the artists Che amounted to alienation and nostalgia. They are close to Arab Civilian. The western extremist clothes of the rebel artists is absent as well as the clothes that indicates the extremely rich economic situation. The director did not use any make-up on his characters. The montage was the dominant movie format that showed the characters' anxiety by employing movie metaphors such as the river scene in referring to the drowning of Iraqis in the Aegean Sea or the scene of musical instruments in the thirty-fifth minute with the singing of the singer Asmahan. The same situation was embodied in the music. The director employed Arab and European music in a controversial struggle between the self and the other.

\section{Chapter Four}

\section{RESULTS AND CONCLUSIONS}

\section{The results}

1. The characters in the Mirrors of the Diaspora suffered from the personal abnormality due to the oppressive religious, political, and social authorities in home country and the problems of integration in the country of emigration.

2. The film of the Diaspora mirrors is full of topics such as natalogy, poverty, alienation, and integration as noted in the characters of Afifa, Al-Allaq, and Al-Dakheel.

3. The cinematic elements, such as photography, lighting, fashion, decoration, sound, and montage, helped highlight the Diaspora cinematography by showing the characters' anxiety, alienation, and problems of identity.

\section{CONCLUSIONS}

1. The oppressive authorities, with all their religious, political and social representations and problems of integration, are among the attributes of the identity problem in the Diaspora movies.

2. Existential alienation, nostalgia, poverty and assimilation are among the most important topics of the Diaspora cinema and they express the problems of identity.

3. The creative employment of the elements of the cinematic language contributes greatly to exposing the problems of identity that the exile directors suffer from, especially as their works greatly simulate reality.

\section{REFERENCES}

A group of authors, Almuheet Dictionary, Cairo, The Arabic Language Academy, $5^{\text {th }}$ edition, 2011, p. 1040.

Alex Machelle, The Identity, Translated by: Asaad Wattfa, Damascus, Dar Al-Rawasem for Publishing and Distribution, 1993, p. 45.

Muhammad Abid Al-Jabri, The Question of Arab Identity, Islam and the West, Beirut, Center for Arab Unity Studies, 2012, p. 46. 
Aristotle's view, logic, Reviewed by: Abd al-Rahman Badawi, Kuwait, Beirut, Publications Agency, Dar AlQalam, 1980.

Friedrich Nietzsche, Zoroaster said so, translated by: Felix Fares, Beirut, International Office for Printing and Publishing, 1979, p. 30.

Michel Foucault, Monitoring and Punishing, Translated by: Ali Muqalled, Beirut, National Development Center, 1990, p. 116.

Edward Saeed, Authority, Politics, and Culture, translated by: Naela Qalqily Hijazi, Beirut, Dar al-Adab for Publishing and Distribution, 2008, p. 50.

Franz Fanon, The Wretched of the Earth, translated by: Sami Al-Droubi and Jamal Al-Atassi, Cairo, Madarat for Research and Publishing, 2014, pp. 35- 36.

Franz Fanon, ibid, p. 81.

Homi K. Bhabha, The Location of Culture, London and New York, Rutledge, 1994, P. 112.

Ali Harb, Identity Speech - An Intellectual Biography, Beirut, Arab Science House - Publishers, 2008, p. 16.

Rami Abu Shihab, In the Last Pass - The Palestinian Diaspora Narrative - From a Post-Colonial Perspective, Beirut, Arab Institute for Studies and Publishing, 2017, p. 42.

Ibn Mandhour, Lisan Al-Arab - part 7, Beirut, House of Arab Heritage Revival - Arab History Foundation, 3rd edition, 1999, p. 26.

The website of the Encyclopedia in the Internet, the Constitutional (Diaspora).

William in Costanzo, International cinema from the perspective of cinematic genres, translated by: Ziad Ibrahim, Cairo, Hindawi CAC Foundation, 2020, p. 320.

Barry Kate Granth, Encyclopedia of Film - Shermer, Part Three, same source, pp. 1022-1023.

Ken Dansagere, The Idea of Film Direction - How to Become a Great Director, translated by Ahmed Youssef, Cairo, National Center for Translation, 2009, p. 136.

Marcel Martin, The Cinematic Language, Translated by: Saad Makawi, Cairo, The Egyptian House of Authorship and Translation, 1964, p. 225. 